\title{
Effect of Zinc Borate on Flammability of PET Woven Fabrics
}

\author{
Mustafa E. Üreyen $\mathbb{D}^{1,2}$ and Elif Kaynak $\mathbb{D}^{3}$ \\ ${ }^{1}$ Department of Fashion and Textile Design, Eskişehir Technical University, Eskişehir 26470, Turkey \\ ${ }^{2}$ Civil Aviation Research Centre, Anadolu University, Eskişehir 26555, Turkey \\ ${ }^{3}$ Chemical Engineering Department, Eskişehir Technical University, Eskişehir 26555, Turkey
}

Correspondence should be addressed to Mustafa E. Üreyen; meureyen@eskisehir.edu.tr

Received 28 October 2018; Revised 6 February 2019; Accepted 11 February 2019; Published 7 March 2019

Academic Editor: Camino Giovanni

Copyright (C) 2019 Mustafa E. Üreyen and Elif Kaynak. This is an open access article distributed under the Creative Commons Attribution License, which permits unrestricted use, distribution, and reproduction in any medium, provided the original work is properly cited.

\begin{abstract}
Zinc borate $(\mathrm{ZnB})$ has been used as a flame retardant, a smoke suppressant, and an antitracking agent in several applications. It may show synergistic effects with antimony oxide and metal hydroxides in fire retardant systems. In this work, the effect of $\mathrm{ZnB}$ on the flame retardancy of PET (poly(ethylene terephthalate)) woven fabrics was investigated. In order to provide the homogenous application of $\mathrm{ZnB}$ to the fabrics, the particle size of $\mathrm{ZnB}$ powders was reduced from $9 \mu \mathrm{m}$ to submicron scale by wet-milling with zirconia balls followed by high shear fluid processing. $\mathrm{ZnB}$ dispersion was mixed with low-formaldehyde melamine resin based cross-linking agent and it was applied to PET fabrics by pad dry cure method. ZnB dispersion was then added in different ratios to alkyl phosphonate and organophosphorus compound based commercial flame retardant finishing agents and applied to the fabrics. The effect of zinc borate with phosphorus based flame retardant (FR) finishing agents was examined by cone calorimetry under a heat flux of $35 \mathrm{~kW} / \mathrm{m}^{2}$, vertical flame test, and limit oxygen index. Thermogravimetric analysis was performed up to $800^{\circ} \mathrm{C}$ under $\mathrm{N}_{2}$ flow. Test results show that zinc borate can be combined with the organophosphorus based commercial FR finishing agents. Zinc borate could not improve the flammability properties of PET fabrics significantly but decreased mean CO, total smoke release, and total smoke production values.
\end{abstract}

\section{Introduction}

PET (poly(ethylene terephthalate)) fiber is the most-used synthetic fiber worldwide thanks to a vast number of technical applications. It has been widely used in household textiles as curtains, upholstery, and mattresses. Moreover, it has frequently been used in transportation textiles. Although PET has good thermal stability, chemical resistance, and excellent mechanical properties, relatively high flammability and the poor antidripping properties of PET restrict its application where specific fire resistance performance is required. Fire statistics show that an important portion of losses and fatalities in domestic fires are caused by synthetic fibers such as polyester $[1,2]$. Polyester fibers may be flame retarded using either one of the following approaches: using flame retardant comonomers during copolymerization, doping FR additives during extrusion, or applying flame retardants on fabrics by finishing or coating techniques [2]. For instance, Trevira $\mathrm{CS}^{\circledR}$ produced by copolymerization of bifunctional organophosphorus compound based on a phosphinic acid derivative is a well-known inherently flame retardant polyester fiber [3]. Commercial flame retardants for thermoplastic polyesters including PET and PBT (polybutylene terephthalate) were reviewed by Weil and Levchik [4]. It was emphasized that phosphorus containing FRs provide adequate performance for PET and PBT. In the recent years, the sol-gel treatment of polyester and its blends has been considered as the sol-gel derived hybrid architectures are able to protect the polymer substrate by forming a barrier against heat and mass transfer $[5,6]$. The treatment of PET fabrics with a silane precursor (3-glyci-dyloxypropyltrimethoxysilane) in the presence of boehmite enhanced the flame resistance of polyester [7]. When PET fabrics were coated with phosphorylated solgel, the LOI of PET fabric was increased from $18 \%$ to $27 \%$; however the suggested treatment requires that the fabrics are exposed to UV/Ozone irradiation before treatment $[8,9]$. 
There is a high demand by the industry for inexpensive, non-halogenated flame retardants which can easily be applied to textiles using conventional equipment. In addition to this, flame retardants should not deteriorate the physical, aesthetic, and physiological properties of textiles. They should also present environmental-friendly and nontoxic features. Although their efficiency is lower than halogen based flame retardants, expensive phosphorus based flame retardants for polyester are preferred, because of low smoke generation, nontoxicity, and low corrosion properties [10-12]. On the other hand, melt dripping of polyester during burning is still a major problem. Therefore, flame retardants for polyester based textiles which promote char formation and reduce melt-dripping behavior are required $[13,14]$. The melt dripping behavior of some commercial flame retardants on PBT has been investigated and it was found that the melt flow and dripping behaviors of polymer were highly dependent on the type and mode of action of flame retardant [15].

Less than $2 \mathrm{wt} \%$ of additives such as metal oxides can change the interaction of phosphorus containing flame retardants with their chemical surroundings during pyrolysis [16]. Combining some additives with phosphorus based flame retardant may enhance the effect of flame retardant agent. Various metal compounds, borates, and inorganic fillers can be used as synergists to phosphorus based flame retardants [16]. Endothermic thermal decomposition of metal hydroxide, carbonate, and boron additives produces noncombustible gasses, such as $\mathrm{H}_{2} \mathrm{O}$ and $\mathrm{CO}_{2}$ diluting the oxygen supply and fuel concentration [17]. Zinc borate has been widely used as a flame retardant, a smoke suppressant, an afterglow suppressant, and an antitracking agent. It has been used with other flame retardants in several polymers such as ethylene vinyl acetate (EVA) [18], polyamide (PA) [19, 20], polyethylene terephthalate (PET) [20], and other polyolefins. It has been previously shown that ultrafine zinc borate particles can reduce the toxicity either by reducing the amount of combustion gases produced due to the improved quality of char or by absorbing $\mathrm{CO}$ and the smoke particles thanks to its small particle size, high surface area, and high specific area [21]. Zinc borate with a chemical formula of $2 \mathrm{ZnO} \cdot 3 \mathrm{~B}_{2} \mathrm{O}_{3} \cdot 3.5 \mathrm{H}_{2} \mathrm{O}$ is stable up to $>290^{\circ} \mathrm{C}$ and this feature allows for its processing with a number of polymers. The number of studies related to the use of zinc borate as a flame retardant for textiles is limited. Agrawal et al. [22] used zinc borate successfully as a flame retardant for polyester; moreover they investigated that flame retardant features presented by zinc borate could further be enhanced when it is used in combination with antimony trioxide. Some researchers have studied the effect of the particle size of $\mathrm{ZnB}$ on flammability. Bourbigot et al. [23] found out that the use of fine zinc borate particles in EVA/alumina trihydrate system provided a better dispersion as the $\mathrm{B}_{2} \mathrm{O}_{3} / \mathrm{ZnO}$ glass formed by the degradation of zinc borate was homogenously distributed in polymer matrix. It was shown that the replacement of $5-10 \mathrm{wt} \%$ magnesium hydroxide by fine grade zinc borate reduced the peak of HRR of EVA and increased char formation [24]. Üreyen [25] investigated the combination of submicron scaled $\mathrm{ZnB}$ powders and organic phosphinate based flame retardant on the flame retardancy of poly(butylene terephthalate). It was found that $\mathrm{ZnB}$ increased the char content but decreased the LOI value.

The ignitability of textile materials is often measured by limiting oxygen index (LOI), horizontal and vertical flammability tests. Despite the cone calorimeter being a good indicator of the combustion behavior of materials, it has rarely been used to test the fire performance of textiles. Thus, very few studies related to the cone calorimeter analyses of textiles have been found in literature. Alonghi et al. [12] applied several nanoparticles and their combinations to polyester, cotton, and polyester/cotton blends and tested their flammability by cone calorimeter under a heat flux of $35 \mathrm{~kW} / \mathrm{m}^{2}$. They have investigated that most of the nanoparticles increase the fire performance index (FPI) value of polyester fabric with low area density $\left(171 \mathrm{~g} / \mathrm{m}^{2}\right)$; however they had very little effect on polyester fabric with high area density $\left(490 \mathrm{~g} / \mathrm{m}^{2}\right)$. Kotresh et al. [26] evaluated the flammability of commercial inherently flame retardant polyester curtain fabric samples by cone calorimetry at $50 \mathrm{~kW} / \mathrm{m}^{2}$. As the area density of fabric increased, important flammability parameters such as the peak heat release rate, total heat released, and $\mathrm{CO}$ yield increased due to the increasing amount of fuel; however effective heat of combustion did not change significantly.

In this work, mean particle size of zinc borate $\left(2 \mathrm{ZnO} \cdot 3 \mathrm{~B}_{2} \mathrm{O}_{3} \cdot 3 \cdot 5 \mathrm{H}_{2} \mathrm{O}\right)$ powders was reduced by attrition milling followed by high shear fluid processing in order to increase its surface area. Powders were then applied to polyester (PET) woven fabrics by pad dry cure method. In addition to this, zinc borate dispersion was added in different ratios to commercial finishing agents and applied to the fabric samples. The effect of zinc borate with phosphorus based flame retardant finishing agents was examined by cone calorimetry, LOI, vertical flame test, and thermogravimetric analysis.

\section{Materials and Methods}

Zinc borate with the chemical formula $2 \mathrm{ZnO} \cdot 3 \mathrm{~B}_{2} \mathrm{O}_{3} \cdot 3.5 \mathrm{H}_{2} \mathrm{O}$ was provided by Great Lake Chemical Corporation/USA under commercial name of ZB-467. Alkyl phosphonate based nonionic flame retardant finishing agent which is acidic in nature $(\mathrm{pH}=2-5)$ was provided by Rudolf $\mathrm{GmbH} / \mathrm{Germany}$ under the commercial name of Rucoflam PSY-E (PSY). Organic cyclic phosphonate compound based finishing agent $(17 \% \mathrm{P})$ which is strongly acidic in nature $(\mathrm{pH}=1.5-1.8)$ was provided by Clariant/Switzerland under commercial name of Pekoflam PES (PEK). The cross-linking agent based on low formaldehyde methylol melamine resin was kindly supplied by $\mathrm{CHT} / \mathrm{Germany}$ under commercial name of Apyrol MH.

PET 2/1 twill woven fabric with a density of $275 \mathrm{~g} / \mathrm{m}^{2}$ was used. In order to remove the impurities and reactive groups remaining on the fabric from previous processing, the fabric samples were washed with a colloidal, complexing chemical agent capable of sequestering ions (Clariant/Switzerland, Ladiquest $1097 \mathrm{~N}$ Liquid). The washing was performed using a wascator (Electrolux, FOM71 CLS) according to ISO 63302002 following $5 \mathrm{~A}$ program. The fabric samples were then dried flat at room temperature. 
TABLE 1: The flame retardant treatment conditions of PET fabrics.

\begin{tabular}{|c|c|c|c|c|c|c|c|c|}
\hline \multirow{2}{*}{$\begin{array}{l}\text { Finishing agent and } \\
\text { application conditions }\end{array}$} & \multicolumn{8}{|c|}{ Quantity (g/l) } \\
\hline & $\mathrm{Z} 50$ & Z100 & Z200 & PSY & PSY-Z20 & PEK & $\begin{array}{r}\text { PEK- } \\
\text { Z25 }\end{array}$ & PEK-Z50 \\
\hline Agent A (PSY) & 0 & 0 & 0 & 80 & 60 & 0 & 0 & 0 \\
\hline Agent B (PEK) & 0 & 0 & 0 & 0 & 0 & 100 & 75 & 50 \\
\hline $\mathrm{ZnB}$ dispersion & 50 & 100 & 200 & 0 & 20 & 0 & 25 & 50 \\
\hline Pick-up (\%) & 92.35 & 91.25 & 90.75 & 87.74 & 97.20 & 90.87 & 90.60 & 89.30 \\
\hline $\mathrm{pH}$ & 5.5 & 5.5 & 5.5 & 5.0 & 5.0 & 6.0 & 6.0 & 6.0 \\
\hline \multirow{2}{*}{ Drying } & $120^{\circ} \mathrm{C}$ & $120^{\circ} \mathrm{C}$ & $120^{\circ} \mathrm{C}$ & $120^{\circ} \mathrm{C}$ & $120^{\circ} \mathrm{C}$ & $120^{\circ} \mathrm{C}$ & $120^{\circ} \mathrm{C}$ & $120^{\circ} \mathrm{C}$ \\
\hline & $2 \mathrm{~min}$. & $2 \mathrm{~min}$. & $2 \mathrm{~min}$. & $1.5 \mathrm{~min}$. & $1.5 \mathrm{~min}$. & $1.5 \mathrm{~min}$. & $1.5 \mathrm{~min}$. & $1.5 \mathrm{~min}$. \\
\hline \multirow{2}{*}{ Curing } & $160^{\circ} \mathrm{C}$ & $160^{\circ} \mathrm{C}$ & $160^{\circ} \mathrm{C}$ & $190^{\circ} \mathrm{C}$ & $190^{\circ} \mathrm{C}$ & $190^{\circ} \mathrm{C}$ & $190^{\circ} \mathrm{C}$ & $190^{\circ} \mathrm{C}$ \\
\hline & $3 \min$ & $3 \mathrm{~min}$. & $3 \mathrm{~min}$. & $1.5 \mathrm{~min}$ & $1.5 \mathrm{~min}$. & $1.5 \mathrm{~min}$. & $1.5 \mathrm{~min}$. & $1.5 \mathrm{~min}$. \\
\hline
\end{tabular}

The particle size of $\mathrm{ZnB}$ was $9 \mu \mathrm{m}$ as obtained. In order to reduce its particle size to submicron scale wet method was selected thanks to the insolubility of $\mathrm{ZnB}$ in water. Stabilizing agents, namely, aluminum sulfate 18-hydrate (AS), sodium silicate (SS), and tri-sodium citrate di-hydrate (TSS) were purchased from Merck KGaA/Germany and used as purchased at certain molar ratios in order to obtain a stable milling media. The particle size and zeta potential of each dispersion after milling was measured by Zetasizer (Malvern, NanoZS 3600). The selected dispersion was then processed by a high shear fluid processor (Microfluidics, M110P) to obtain a more homogenous and stable solution. $\mathrm{ZnB}$ powders were characterized by XRD (Rigaku, Miniflex 600) with CuK- $\alpha$ radiation before and after milling.

All types of flame retardant agents were applied to fabric samples by using a laboratory vertical padder (ATAC, F350). The treatment conditions of commercial agents were chosen as to comply with the conditions recommended by the manufacturers. Firstly, finishing baths were prepared adding various concentrations of $\mathrm{ZnB}$ solution $(50-200 \mathrm{~g} / \mathrm{L}$ ) to evaluate the flame retardant performance of $\mathrm{ZnB}$ powders alone. The cross-linking agent was based on low formaldehyde melamine resin and was also added to each finishing bath $(20 \mathrm{~g} / \mathrm{L})$ in order to provide washing durability. Following the padding, fabric samples were dried and cured in a laboratory stenter (Rapid, minidryer QCA 1708).

A $25 \%$ of PSY, 25\% PEK, and 50\% PEK were replaced by the zinc borate solution and applied to the fabrics to see the effects of ZnB (PSY-Z20, PEK-Z25, and PEK-Z50). The solution $\mathrm{pH}$ was adjusted by phosphoric acid. In order to eliminate the deteriorating effects of phosphoric acid, the fabric samples were washed in Wascator machine according to same standard used for washing the neat fabric after being treated with sodium carbonate $(15 \mathrm{~g} / \mathrm{L})$ for neutralization. Commercial finishing agents and $\mathrm{ZnB}$ combinations were applied to the fabric samples. The treatment conditions of all applications are tabulated in Table 1.

The fire performance of the treated fabrics was evaluated by limit oxygen index (LOI) test, vertical flammability test, and cone calorimeter. The LOI tests were performed using an LOI test equipment (Dynsco) following ASTM D 2863-00 standard. Vertical flammability tests of fabric samples $(76 \mathrm{~mm}$ $\times 300 \mathrm{~mm}$ ) were performed using a vertical flammability test chamber (SDL Atlas) following ASTM D 6413-08 standard. The samples were exposed to the flame for 12 seconds. Afterflame time (the length of time the material continues to burn after removal of the burner), after-glow time (the length of time the material glows after the flame extinguishes), and char length were measured. Cone calorimeter (Fire Testing Technology, FTT) was used to investigate the combustion behavior of square samples $(100 \mathrm{~mm} \times 100 \mathrm{~mm} \times 0.6 \mathrm{~mm})$ according to ISO 5660 standard. The heat flux chosen was $35 \mathrm{~kW} / \mathrm{m}^{2}$ as it was previously proposed as the heat flux that can adequately represent a mild fire scenario [27]. Time to ignition (TTI, s), heat release rate (HRR, $\mathrm{kW} / \mathrm{m}^{2}$ ), and corresponding peak HRR, time to peak HRR (s), total heat release (THR, $\mathrm{kW} / \mathrm{m}^{2}$ ), and mean MLR (g/s) were measured. Mean $\mathrm{CO}$ and $\mathrm{CO}_{2}$ release $(\mathrm{kg} / \mathrm{kg})$, total smoke release (TSR, $\mathrm{m}^{2} / \mathrm{m}^{2}$ ), and total smoke production (TSP, $\mathrm{m}^{2}$ ) were also evaluated. The fire performance index (FPI, $\mathrm{sm}^{2} / \mathrm{kW}$ ) was also calculated as TTI to pHRR ratio. It was calculated in order to establish a ranking of the most effective application for improving the flame retardancy of polyester fabric samples. It is claimed that the higher the FPI, the better the flame-retardant performance presented by the sample [12]. All fabric samples were conditioned in a climatic chamber at $23 \pm 1^{\circ} \mathrm{C}, 50 \%$ relative humidity for $24 \mathrm{~h}$ before the tests.

The thermal stability of the fabrics was evaluated by thermogravimetric analyses (TGA) in nitrogen from 30 to $800^{\circ} \mathrm{C}$ with a heating rate of $10^{\circ} \mathrm{C} / \mathrm{min}$ by using Netzsch/STA 409 PG and TA Instruments SDT Q600.

Fabric morphologies were examined by scanning electron microscopy (SEM, Zeiss Evo 50EP) at $15 \mathrm{kV}$.

The durability and washing fastness of FR treated fabrics were also tested, and the samples were washed several times by a Wascator following the same standard used for washing the neat fabric.

\section{Results and Discussion}

3.1. Particle Size Reduction of $\mathrm{ZnB}$. $\mathrm{ZnB}$ powders were milled to reduce the particle size by attrition milling in distilled 
TABLE 2: Particle size and zeta potential test results of $\mathrm{ZnB}$ after attrition milling.

\begin{tabular}{lccc}
\hline Stabilizing Agent & Quantity $(\mathrm{mol} / \mathrm{l})$ & Mean particle size $(\mathrm{nm})$ & Zeta Potential $(\mathrm{mV})$ \\
\hline \multirow{3}{*}{ AS } & 0.04 & $1,092.0$ & -8.98 \\
& 0.08 & 882.2 & -0.299 \\
& 0.12 & $1,169.0$ & -4.11 \\
\hline \multirow{2}{*}{ SS } & 0.16 & 874.1 & -0.675 \\
& 0.04 & 719.9 & -6.63 \\
& 0.08 & 1147 & -9.83 \\
\hline & 0.12 & 650.8 & -6.68 \\
TSS & 0.16 & 758.3 & -4.86 \\
& 0.04 & 758.0 & -35.3 \\
& 0.08 & 772.2 & -48.6 \\
\hline
\end{tabular}

TABLE 3: Effect of $\mathrm{pH}$ on zeta potential value.

\begin{tabular}{lc}
\hline $\mathrm{pH}$ & Zeta potential $(\mathrm{mV})$ \\
\hline 4.0 & $-4,91$ \\
5.0 & $-19,8$ \\
6.0 & $-32,1$ \\
7.0 & $-46,9$ \\
\hline
\end{tabular}

water according to the process described in literature [25]. As the sizes of particles are reduced, the particles tend to agglomerate due to increase in surface energy and thermodynamic unsteadiness [28]. Stabilizers are used to prevent agglomeration caused by either the surface potential or steric stabilization. Several surfactants, ligands, or polymers having functional groups can be used for this purpose [29].

Aluminum sulphate-18 hydrate $\left(\mathrm{Al}_{2} \mathrm{O}_{12} \mathrm{~S}_{3} \cdot 18 \mathrm{H}_{2} \mathrm{O}\right)(\mathrm{AS})$, sodium silicate (SS), and tri-sodium citrate di-hydrate (TSS) were selected and added to $\mathrm{ZnB}$ dispersion in different ratios during the milling. The effects of stabilizing agent on size reduction process have been studied and the results are presented in Table 2. Negative zeta potential values were obtained independent of the stabilizing agent used. Zeta potential value approached zero when AS and SS were used during milling. The use of TSS resulted in better zeta potential and lower average particle size values than the other stabilizing agents. Additionally, TSS does not exhibit toxic behavior and cause allergic reactions. Therefore the use of TSS was considered. After attrition milling with TSS, the samples were processed with high shear fluid processor and the average particle size was reduced further to $498.1 \mathrm{~nm}$.

It has been shown that $\mathrm{pH}$, ionic strength, and concentration of electrolytes should be evaluated when the colloidal stability is enhanced electrostatically by sodium citrate [30]. Therefore, the effect of $\mathrm{pH}$ and electrolytes on zeta potential and size values has been investigated. The change in zeta potential with respect to $\mathrm{pH}$ is shown in Table 3 for the $\mathrm{ZnB}$ sample milled using $0.08 \mathrm{~mol} / \mathrm{l}$ of sodium citrate. The $\mathrm{pH}$ has been adjusted by adding phosphoric acid dropwise. The zeta potential approached zero as the $\mathrm{pH}$ decreased. At $\mathrm{pH}=7$, the value of zeta potential was $-46.9 \mathrm{mV}$ and at $\mathrm{pH}=4$ the value measured was $-4.91 \mathrm{mV}$.

Sodium sulfate $\left(\mathrm{Na}_{2} \mathrm{SO}_{4}\right)$ was also added to the milling media to evaluate the effect of electrolyte on the particle size. The particle size of $\mathrm{ZnB}$ was reduced to $139 \mathrm{~nm}$ after milling in attritor mill followed by processing in high shear fluid processor. The zeta potential value of this sample was measured as $-80.4 \mathrm{mV}$. The zeta potential and size distribution of $\mathrm{ZnB}$ is shown in Figure 1.

3.2. Characterization of $\mathrm{ZnB}$ Powders. The XRD plot of $\mathrm{ZnB}$ (ZB-467) powder is shown in Figure 2(a). The plot confirms the chemical formula of the $\mathrm{ZnB}$ as $2 \mathrm{ZnO} \cdot 3 \mathrm{~B}_{2} \mathrm{O}_{3} \cdot 3.5 \mathrm{H}_{2} \mathrm{O}$. The $\mathrm{XRD}$ peak intensities were lower for the milled $\mathrm{ZnB}$ (using $0.08 \mathrm{~mol} / \mathrm{l}$ TSS as stabilizer) as can be seen in Figure 2(b). The reduction in peak intensities may be attributed to a more amorphous structure formed due to milling. When the $\mathrm{ZnB}$ solution $\mathrm{pH}$ was reduced after milling $(\mathrm{pH}=4)$, the XRD pattern changed significantly (Figure 2(c)). This result indicates the $\mathrm{ZnB}$ which may have been partially hydrolysed in acidic media, tended to recrystallize upon drying.

The particle size of $\mathrm{ZnB}$ (ZB-467) was measured as $9.627 \mu \mathrm{m}$ and the results were confirmed by the SEM images (Figure 3).

TGA and DTA plots of $\mathrm{ZnB}(\mathrm{ZB}-467)$ are shown in Figure 4. The mass loss of $\mathrm{ZnB}$ starts at $300^{\circ} \mathrm{C}$ and it was measured as approximately $12 \%$ between 300 and $420^{\circ} \mathrm{C}$ and $14.5 \%$ between 300 and $600^{\circ} \mathrm{C}$.The first endothermic reaction was observed at approximately $90^{\circ} \mathrm{C}$ due to the loss of moisture and another endotherm was identified within the range of $350-420^{\circ} \mathrm{C}$ possibly due to the dehydration [31]. Yang et al. [32] found that $\mathrm{ZnB}$ is mainly low temperature type $\alpha-\mathrm{ZnO} \cdot \mathrm{B}_{2} \mathrm{O}_{3}$ in the range of $600-700^{\circ} \mathrm{C}$, and $\alpha$ $\mathrm{ZnO} \cdot \mathrm{B}_{2} \mathrm{O}_{3}$ and $\beta-\mathrm{ZnO} \cdot \mathrm{B}_{2} \mathrm{O}_{3}$ coexist in equilibrium at 700 $900^{\circ} \mathrm{C}$. Endothermic peaks at $860^{\circ} \mathrm{C}$ and $970^{\circ} \mathrm{C}$ show the melting of $\alpha-\mathrm{ZnO} \cdot \mathrm{B}_{2} \mathrm{O}_{3}$ and $\beta-\mathrm{ZnO} \cdot \mathrm{B}_{2} \mathrm{O}_{3}$, respectively.

3.3. Scanning Electron Microscopy Analysis Results. In order to assess the morphology of the fabric surfaces after the flame retardant applications, SEM observations have been 


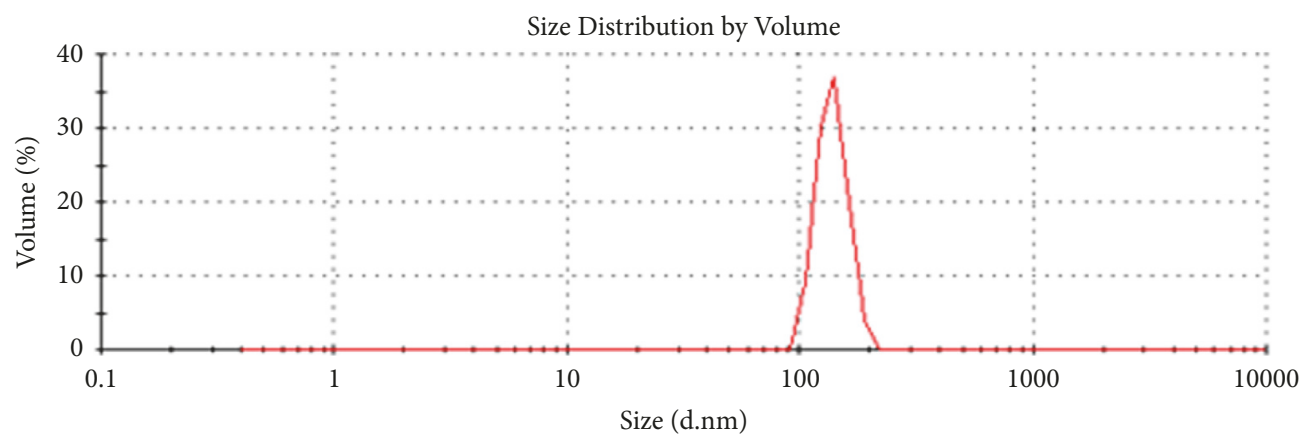

(a)

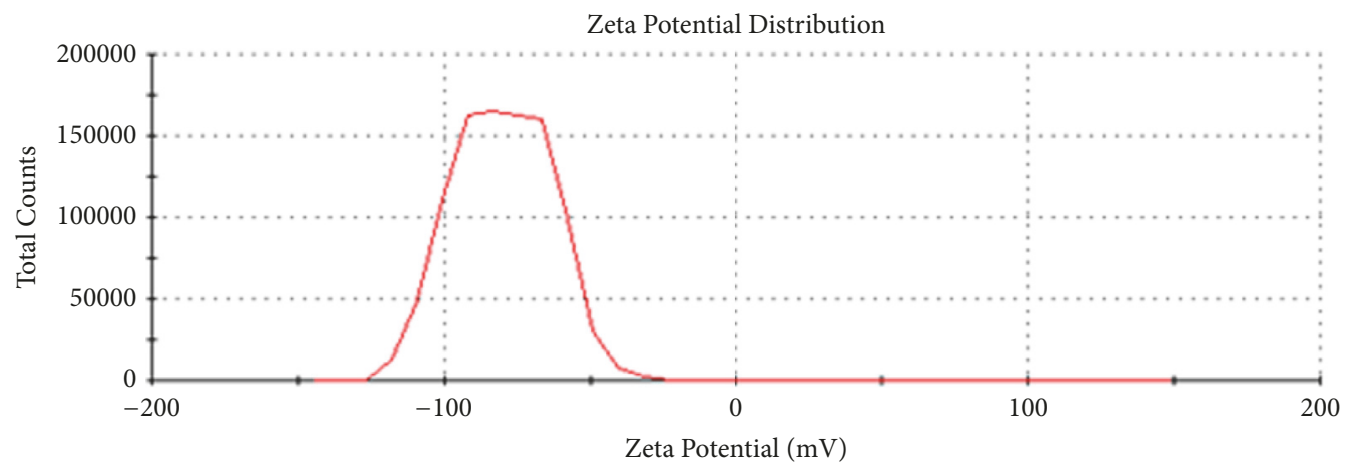

ZnB-TSS-S

(b)

Figure 1: (a) Particle size distribution and (b) zeta potential plots of $\mathrm{ZnB}$ milled by using sodium citrate and sodium sulfate.

TABLE 4: TGA test results of the samples.

\begin{tabular}{lcccc}
\hline & $\mathrm{T}_{10 \%}$ & $\mathrm{~T}_{50 \%}$ & $\begin{array}{c}\text { Residue at } \\
500^{\circ} \mathrm{C}(\%)\end{array}$ & $\begin{array}{c}\text { Residue at } \\
600^{\circ} \mathrm{C}(\%)\end{array}$ \\
\hline REF. & 404 & 432 & 10.61 & 9.19 \\
Z50 & 396 & 424 & 17.34 & 15.68 \\
Z100 & 398 & 427 & 18.74 & 17.09 \\
Z200 & 400 & 429 & 19.74 & 17.95 \\
PSY & 391 & 430 & 16.45 & 14.86 \\
PSY-Z20 & 394 & 428 & 14.02 & 12.17 \\
PEK & 397 & 431 & 14.28 & 12.67 \\
PEK-Z25 & 398 & 430 & 13.64 & 11.94 \\
PEK-Z50 & 401 & 432 & 12.23 & 10.29 \\
\hline
\end{tabular}

carried out. SEM micrographs of reference PET fabric and Z100 sample are shown in Figure 5. SEM images confirm that the particle size of $\mathrm{ZnB}$ was reduced to submicron scale successfully and the particles were homogenously distributed on the fiber surface. SEM images of PET fabrics treated with commercial flame retardants and zinc borate are shown in Figures 6 and 7. The zinc borate particles attached to the fabrics surfaces can be seen in these figures.

3.4. Thermogravimetric Analysis Results. Figure 8 shows the TGA curves of fabrics. The degradation of untreated PET initiated at about $350^{\circ} \mathrm{C}$ and a one-step degradation was observed up to $450^{\circ} \mathrm{C}$. Similar trends were observed for the degradation of FR treated PET fabrics with increasing temperature. The temperature of $10 \%$ and $50 \%$ weight loss and the char residue at $500^{\circ} \mathrm{C}$ and $600^{\circ} \mathrm{C}$ are summarized in Table 4. $\mathrm{ZnB}$, when used alone, increased the char yield; however its combination with commercial agents resulted in lower residual char. The highest char residue was obtained with Z200 sample. As expected, the flame retardant additives slightly reduced the onset decomposition temperature of polyester fabric. Flame retardant treated fabrics show the same degradation mechanisms as reference fabric. 


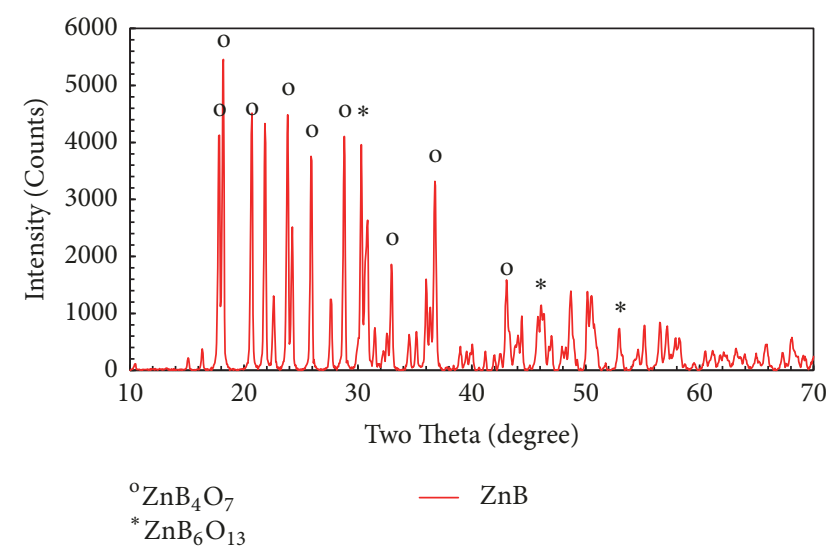

(a)

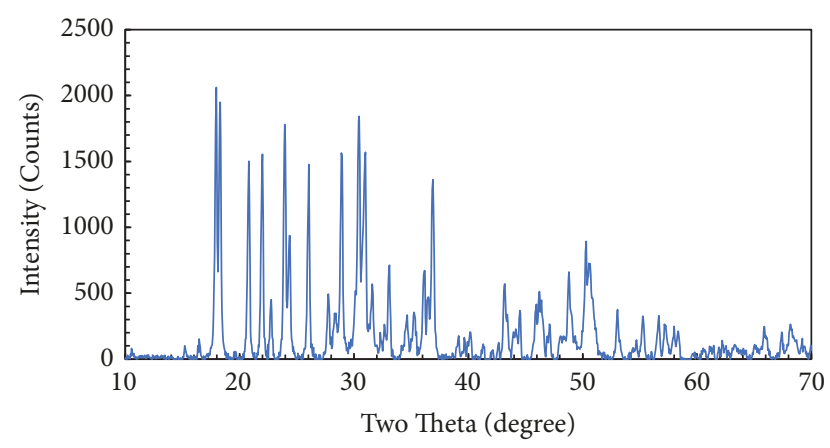

(b)

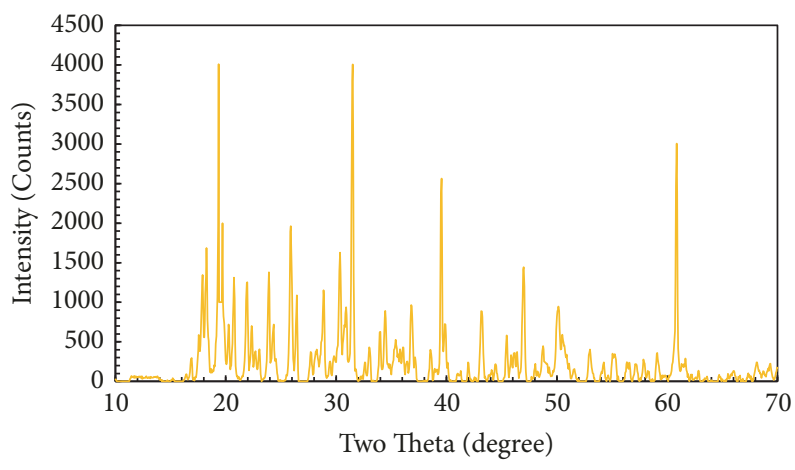

(c)

FIGURE 2: XRD patterns of $\mathrm{ZnB}$ (a) as received, (b) after milling, and (c) after milling (pH=4).

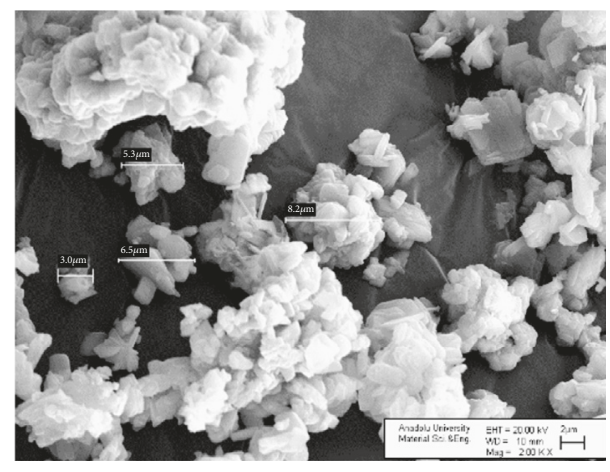

Figure 3: SEM image of $\mathrm{ZnB}$ powder (2,000X).

3.5. LOI Test Results. The limit oxygen index (LOI) values of polyester fabrics treated with flame retardant agents are shown in Table 5. The highest LOI value $(33.8 \%)$ was obtained for the fabric treated with organophosphorus based finishing agent. The LOI of the polyester fabric samples treated with alkyl phosphonate based finishing agent (PSY) was $31.3 \%$. ZnB when used alone increased the LOI of neat PET fabrics. The LOI increased with the increasing $\mathrm{ZnB}$ concentration. The desired level of washing-fastness has been achieved thanks to the cross-linking agent. Moreover, without sacrificing flame retardancy, washing may be applied as a posttreatment in order to reduce the amount of formaldehyde on the finished fabrics [33].

When the commercial flame retardant agent was partially replaced with ZnB (PSY-Z), LOI was decreased. The effect of $\mathrm{ZnB}$ on LOI of PEK-Z25 was not significant; however LOI of PEK-Z50 was slightly lower as the total amount of flame retardants was reduced.

3.6. Cone Calorimetry Test Results. HRR curves of samples obtained by cone calorimeter tests are shown in Figure 9 . The flame retardant treatment of fabrics caused a reduction in pHRR. Excluding fabrics treated with PEK and PEKzinc borate time to peak HRR values were also decreased. Important flammability parameters obtained by the cone calorimeter are presented in Table 6. TTI values of fabrics treated with $\mathrm{ZnB}$ were reduced possibly due to the lower thermal stability of stabilizing agent used for milling and binder used to enhance washing-fastness. The early degradation of the binder and stabilizing agent could lead to the increase of combustible volatiles TTI values as the concentration of $\mathrm{ZnB}$ increased. Zinc borate acts as an insulation barrier for the transfer of heat and oxygen to the fabric besides cooling the substrate by endothermic reactions [34]. Therefore, TTI values were increased and $\mathrm{pHRR}$ values were decreased for samples treated with $\mathrm{ZnB}$. Accordingly, FPI values of these 


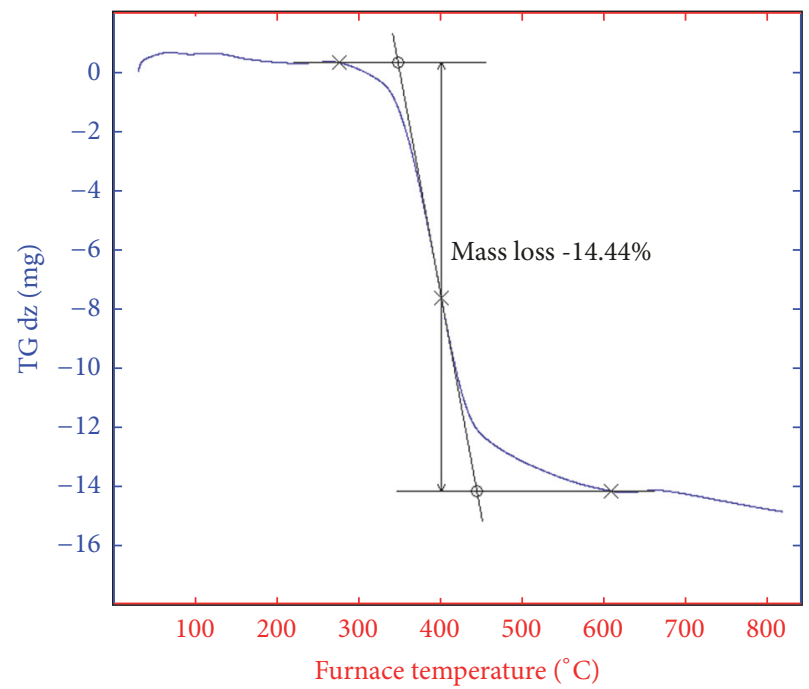

(a)

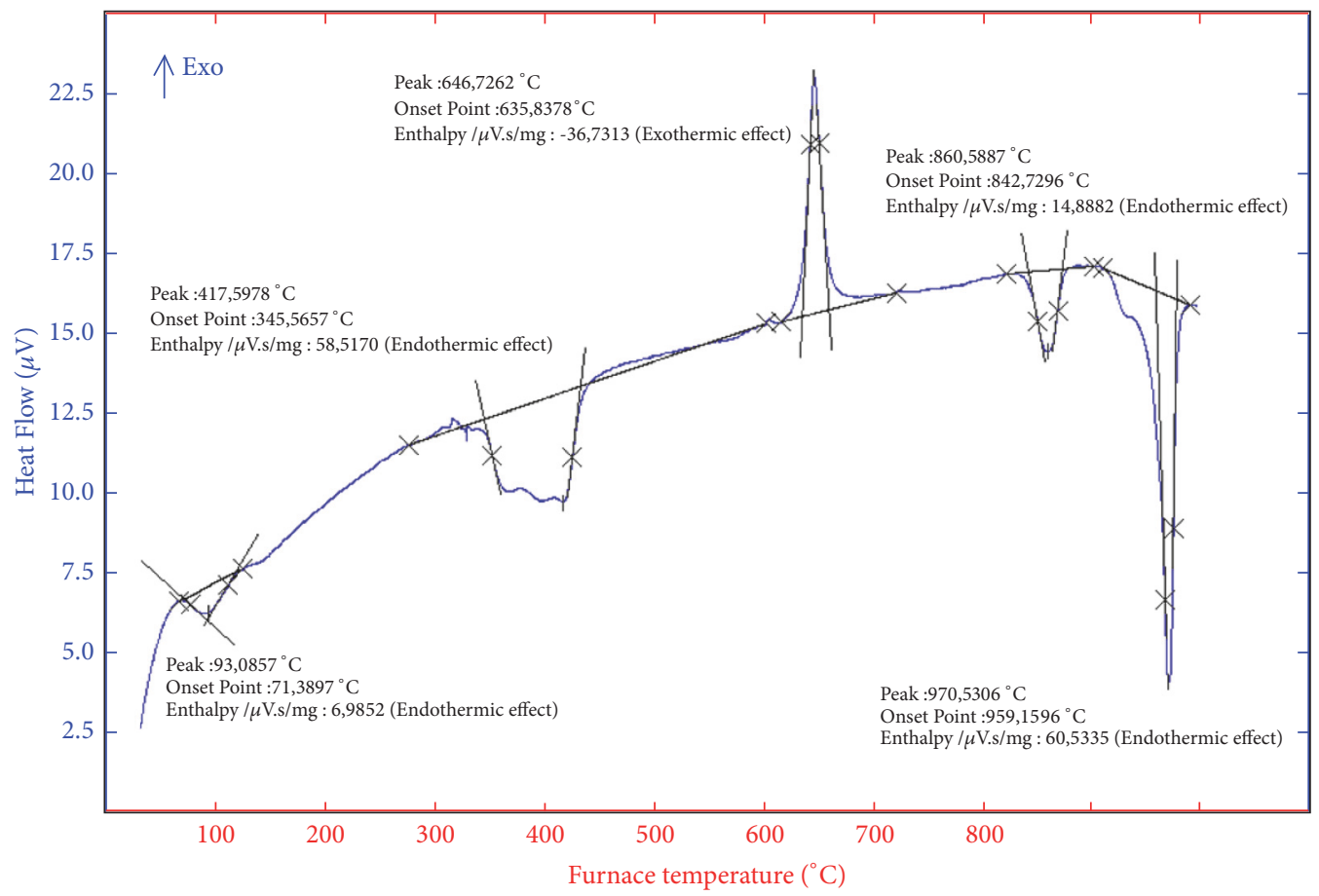

(b)

Figure 4: (a) TGA and (b) DTA curves of ZnB.

samples were lower than the value calculated for the untreated fabric except for the sample treated with $200 \mathrm{~g} / \mathrm{L} \mathrm{ZnB}$ and sample treated only with PSY than those treated with PSY and $\mathrm{ZnB}$. However, the incorporation of $\mathrm{ZnB}$ reduced the mean $\mathrm{CO}$ yield and total smoke produced. Similar conclusions were made with the results of sample treated with only PEK and sample treated with PEK and ZnB except for TTI values. The TTI value of PSY-Z20 was higher than PSY. As the amount of $\mathrm{ZnB}$ particles deposited on fabric surface increases, the value of TTI increases due to the formation of a protective layer which delays ignition.
From the cone calorimeter results, it is obvious that $\mathrm{ZnB}$ reduced mean $\mathrm{CO}$ yield, total smoke release, and smoke production values. These results confirm that $\mathrm{ZnB}$ particles slow down the production of volatile species and promote char formation.

3.7. Vertical Flame Test Results. Flammability of treated fabrics was evaluated in terms of vertical flame test. Figure 10 shows images of reference sample and all flame retardant treated fabric samples. Test results are given in Table 7 . In terms of flammability, favourable results were obtained for 


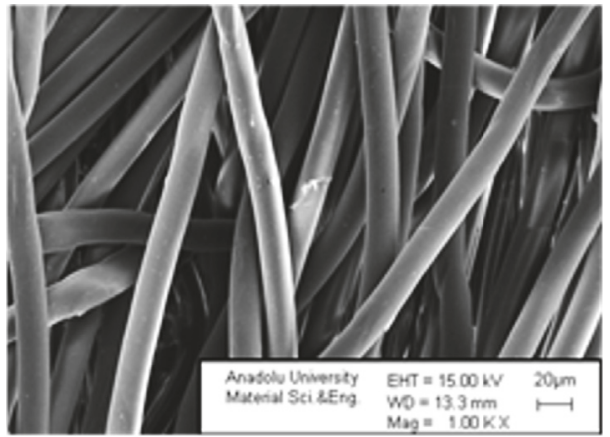

(a)

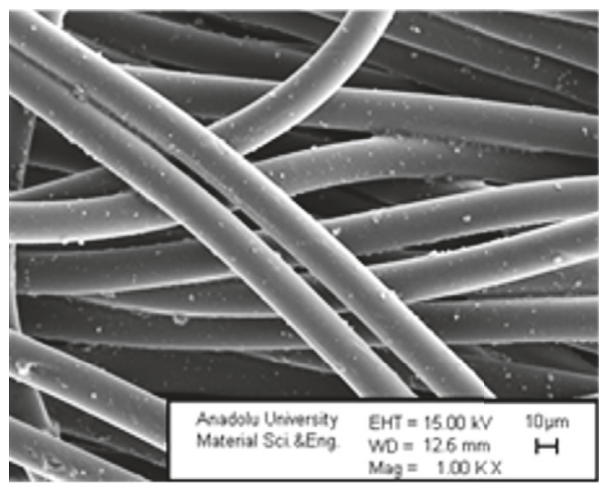

(c)

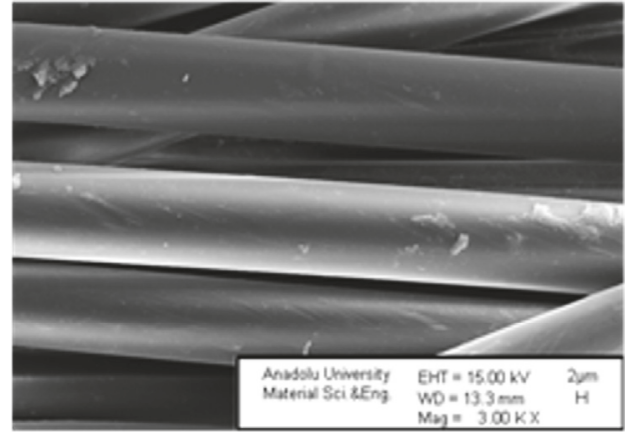

(b)

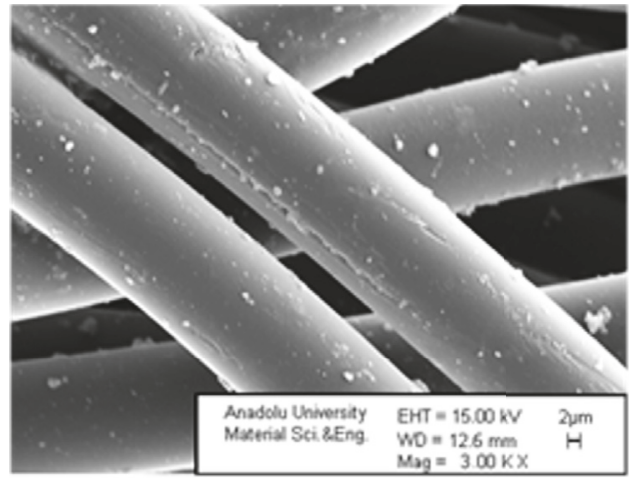

(d)

FIGURE 5: SEM test results of fabric samples. (a) Reference fabric (1,000X); (b) reference fabric (3,000X); (c) Z100 (1,000X); (d) Z100 (3,000X).

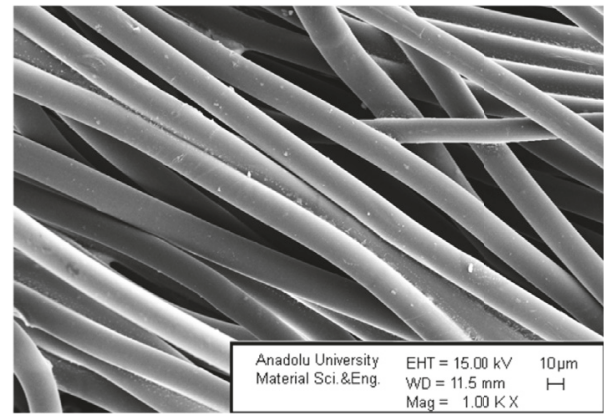

(a)

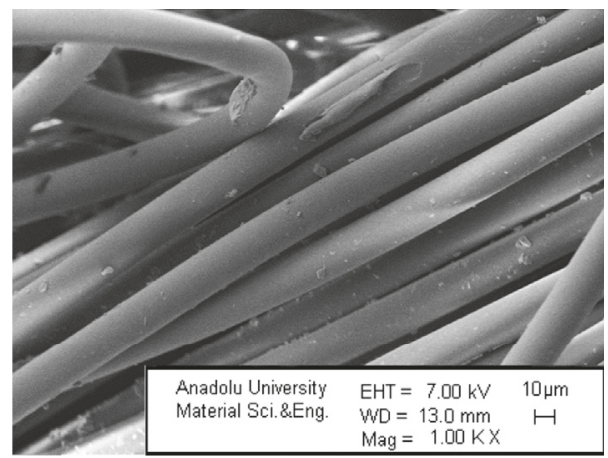

(c)

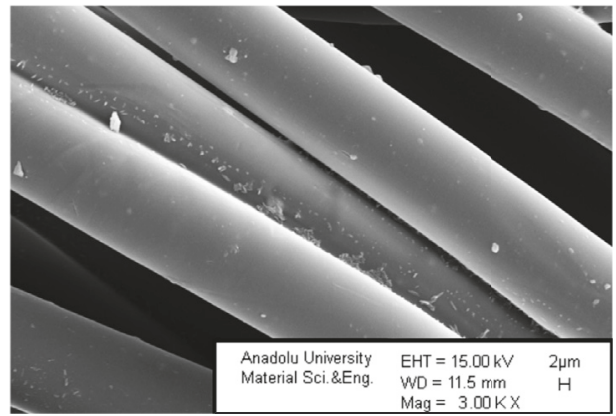

(b)

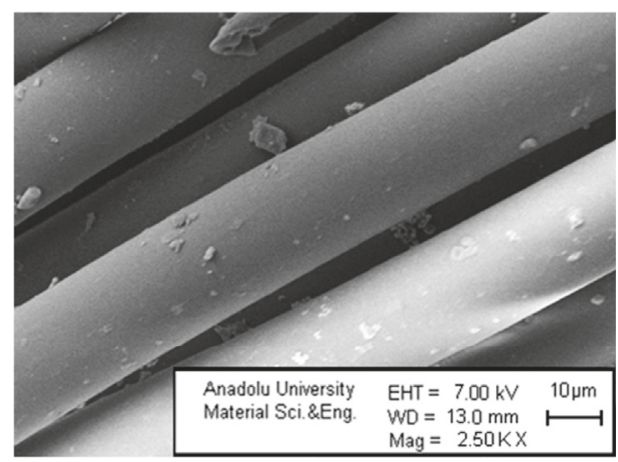

(d)

FIGURE 6: SEM test results of fabric samples. (a) PSY (1,000X); (b) PSY (3,000X); (c) PSY-Z20 (1,000X); (d) PSY-Z20 (2,500X). 


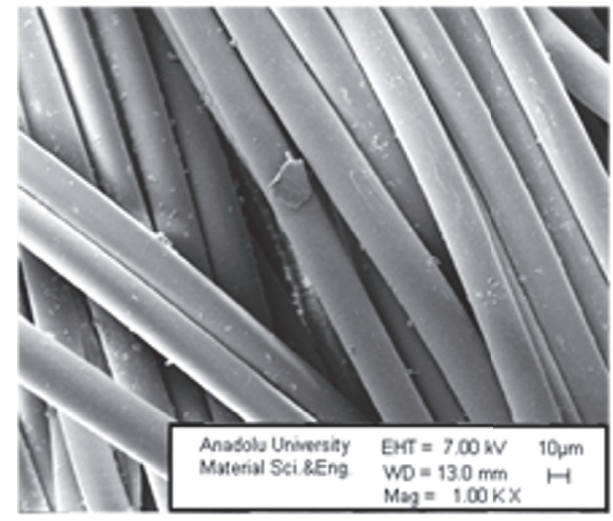

(a)

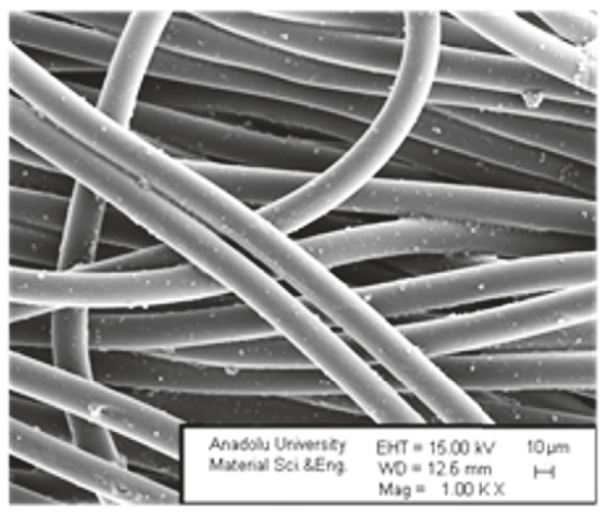

(c)

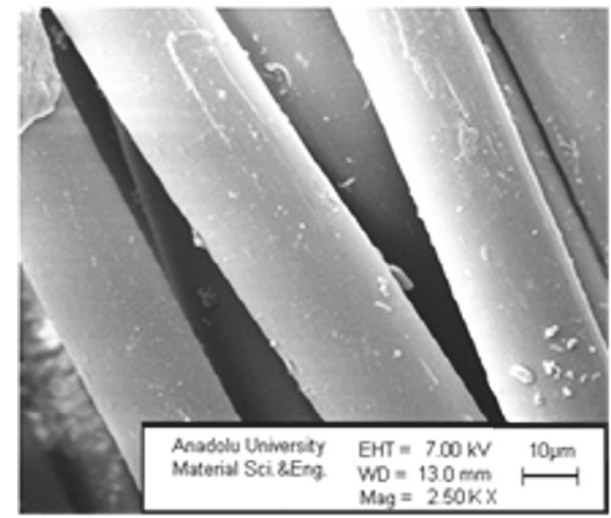

(b)

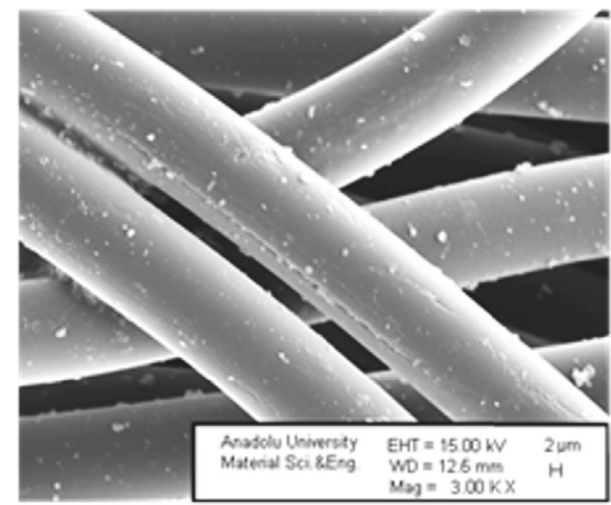

(d)

Figure 7: SEM test results of fabric samples. (a) PEK (1,000X); (b) PEK (2,500X); (c) PEK-Z25 (1,000X); (d) PEK-Z25 (3,000X).

TABLE 5: LOI test results of the samples.

\begin{tabular}{lccccccccc}
\hline \multirow{2}{*}{ Washing cycle } & & \multicolumn{9}{c}{ LOI (\%) } \\
& Ref. & Z50 & Z100 & Z200 & PSY & PSY-Z20 & PEK & PEK-Z25 & PEK-Z50 \\
\hline 0 & 21 & 21.9 & 22.9 & 23.1 & 31.3 & 24.4 & 33.8 & 33.5 & 31.0 \\
10 & - & 21.5 & 22.0 & 23.0 & 30.6 & 24.2 & 33.5 & 33.0 & 30.2 \\
20 & - & 21.5 & 22.0 & 22.5 & 29.9 & 24.0 & 33.5 & 33.0 & 29.7 \\
\hline
\end{tabular}

TABLE 6: Cone calorimeter test results of all samples.

\begin{tabular}{|c|c|c|c|c|c|c|c|c|c|}
\hline \multirow{2}{*}{ Parameter } & \multicolumn{9}{|c|}{ Sample code } \\
\hline & REF. & $\mathrm{Z} 50$ & $\mathrm{Z} 100$ & $\mathrm{Z} 200$ & PSY & PSY-Z20 & PEK & PEK-Z25 & PEK-Z50 \\
\hline TTI (s) & 71 & 47 & 50 & 52 & 65 & 58 & 73 & 76 & 70 \\
\hline t peak HRR (s) & 85 & 65 & 65 & 65 & 75 & 70 & 85 & 90 & 85 \\
\hline peak HRR $\left(\mathrm{kW} / \mathrm{m}^{2}\right)$ & 447.85 & 326.42 & 318.45 & 303.65 & 232.34 & 267.99 & 247.81 & 268.35 & 332.34 \\
\hline $\operatorname{THR}\left(\mathrm{MJ} / \mathrm{m}^{2}\right)$ & 6.522 & 7.850 & 7.840 & 7.079 & 6.132 & 8.926 & 6.376 & 6.211 & 7.099 \\
\hline mean MLR $(\mathrm{g} / \mathrm{s})$ & 0.014 & 0.015 & 0.015 & 0.014 & 0.016 & 0.015 & 0.016 & 0.017 & 0.016 \\
\hline FPI $\left(\mathrm{m}^{2} \bullet \mathrm{s} / \mathrm{kW}\right)$ & 0.159 & 0.144 & 0.157 & 0.171 & 0.280 & 0.216 & 0.295 & 0.283 & 0.211 \\
\hline mean COY $(\mathrm{kg} / \mathrm{kg})$ & 0.132 & 0.121 & 0.130 & 0.123 & 0.234 & 0.190 & 0.160 & 0.124 & 0.112 \\
\hline mean CO2Y (kg/kg) & 1.510 & 1.542 & 1.661 & 1.601 & 1.159 & 1.183 & 1.237 & 1.170 & 1.470 \\
\hline $\operatorname{TSR}\left(\mathrm{m}^{2} / \mathrm{m}^{2}\right)$ & 167.06 & 168.79 & 154.01 & 154.44 & 263.58 & 210.84 & 290.54 & 276.85 & 235.09 \\
\hline$(\mathrm{TSP})\left(\mathrm{m}^{2}\right)$ & 1.477 & 1.492 & 1.361 & 1.365 & 2.330 & 1.864 & 2.568 & 2.447 & 2.078 \\
\hline
\end{tabular}




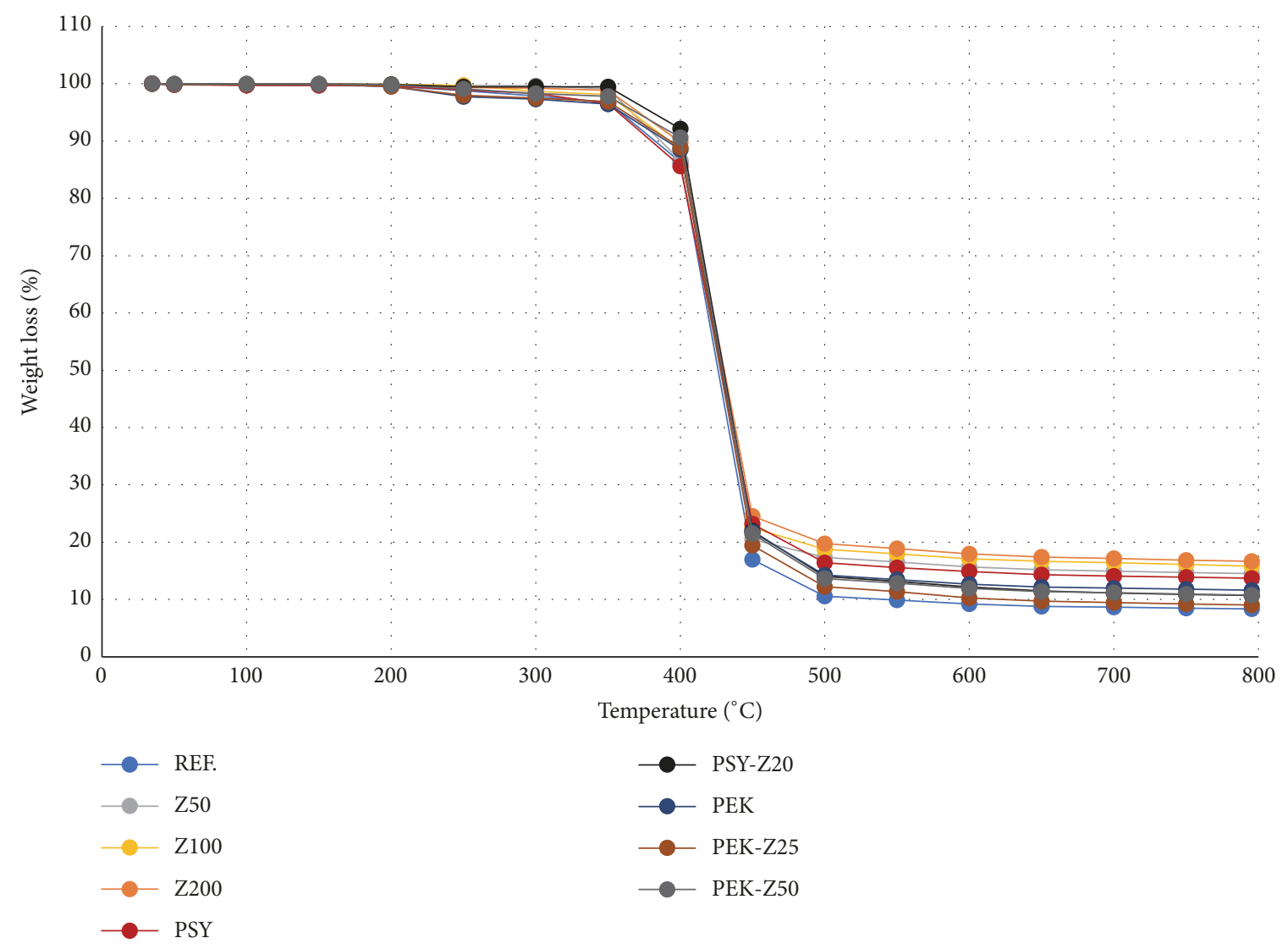

Figure 8: TGA curves of the samples.

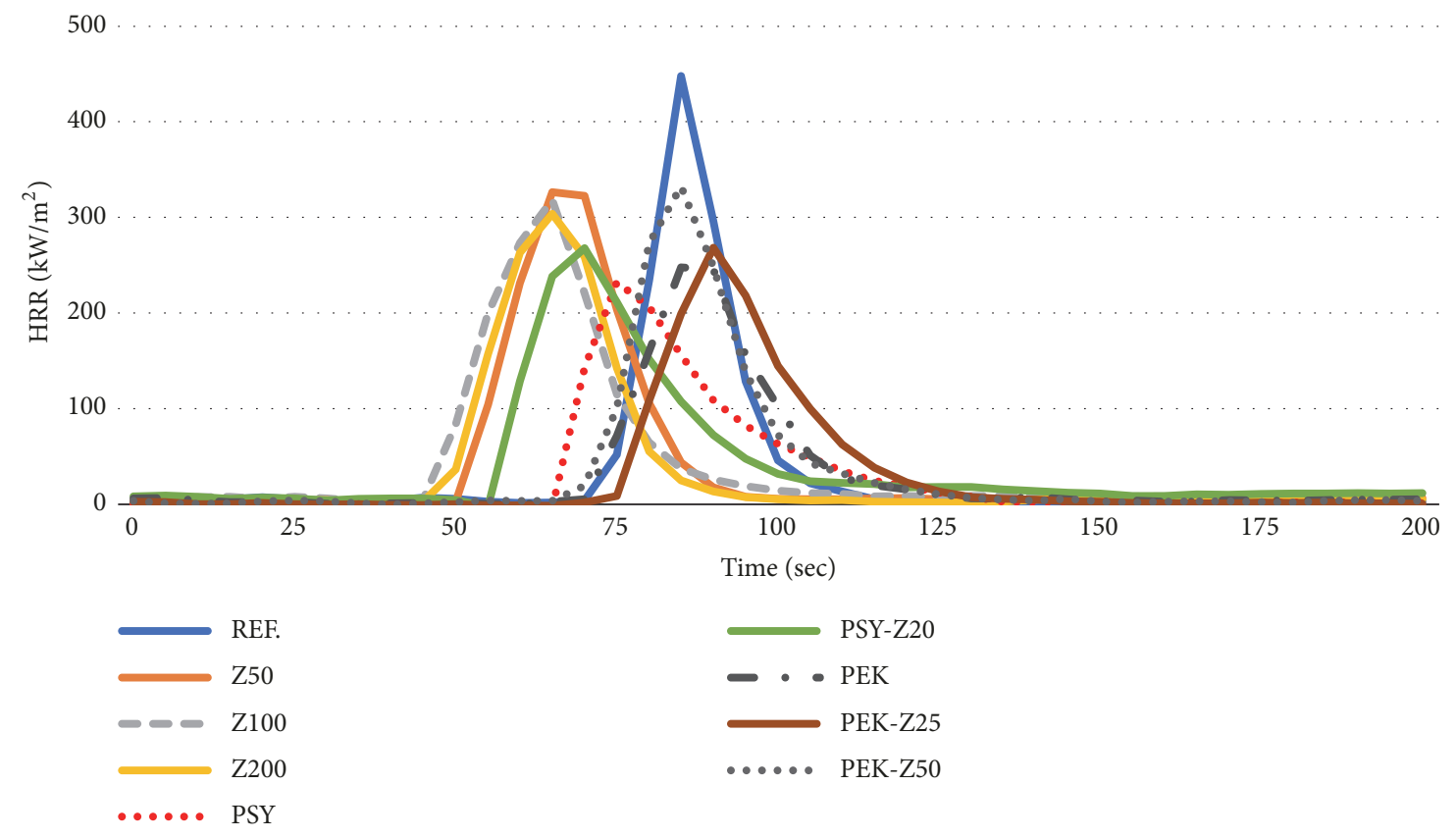

FIGURE 9: HRR curves of all samples. 


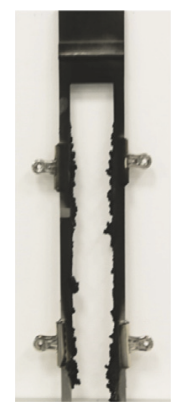

(a)

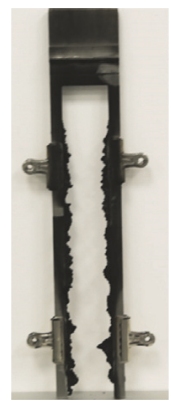

(b)

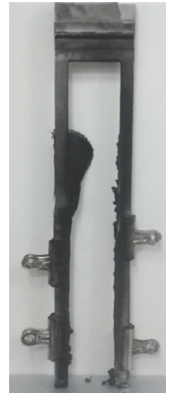

(c)

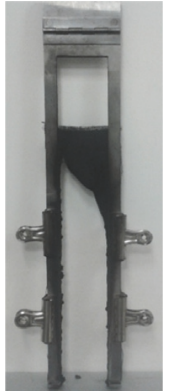

(d)

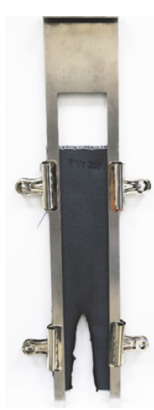

(e)

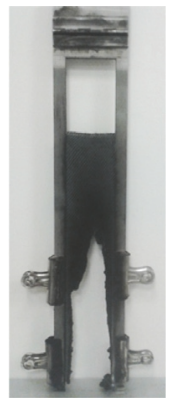

(f)

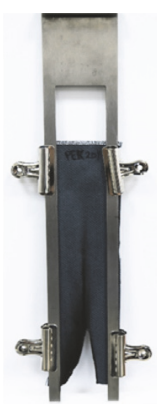

(g)

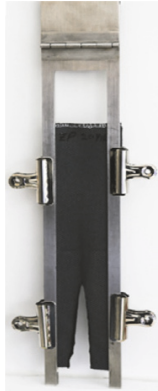

(h)

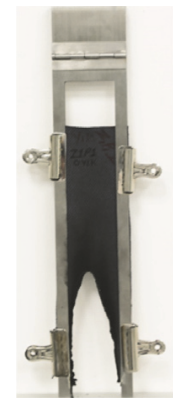

(i)

Figure 10: Fabrics after vertical flammability test. (a) Reference fabric; (b) Z50; (c) Z100; (d) Z200; (e) PSY; (f) PSY-Z20; (g) PEK; (h) PEK-Z25; (i) PEK-Z50.

TABLE 7: Vertical flame test results of all fabric samples.

\begin{tabular}{lcccc}
\hline & After-flame time (s) & After-glow time (s) & Char length (mm) & Dripping \\
\hline REF. & --- & -- & -- & -- \\
Z50 & --- & -- & --- & Yes \\
Z100 & -- & --- & 276 & Yes \\
Z200 & 24.7 & --- & 74 & Yo \\
PSY & 3.3 & 0 & 179 & Yes \\
PSY-Z20 & 14.0 & 0 & 67 & Yes \\
PEK & 2.3 & 0 & 83 & Yes \\
PEK-Z25 & 3.0 & 0 & 129 & Yes \\
PEK-Z50 & 4.2 & 0 & &
\end{tabular}

polyester fabrics treated with commercial flame retardants. Samples treated only with $\mathrm{ZnB}$, namely, Z50 and Z100, completely burned but Z200 did not completely burn due to higher amount of $\mathrm{ZnB}$ used. Increasing the amount of $\mathrm{ZnB}$ applied improves the flammability of polyester fabrics. The replacement of $\mathrm{ZnB}$ partially with the commercial flame retardants did not further improve the flammability. After flame time and char length were increased, zinc borate was concluded to be more compatible with PEK. The incorporation in $\mathrm{ZnB}$ reduced the dripping behaviour and increased char formation.

\section{Conclusions}

Particle size of zinc borate has been reduced from $9 \mu \mathrm{m}$ to $758 \mathrm{~nm}$ by attrition milling and further to $498.1 \mathrm{~nm}$ by high shear fluid processing in the presence of TSS. When sodium sulfate was added to the milling media, the measured particle size of $\mathrm{ZnB}$ was reduced to $139 \mathrm{~nm}$ as a result of the increase in overall ionic strength.

When zinc borate solutions were applied to the polyester woven fabrics, the final residue increased in thermogravimetric analysis (Table 4). Treatment with flame retardants PSY and PEK also led to an increase in the final residue. However, replacement of $25 \%$ of neither PSY nor PEK by $\mathrm{ZnB}$ resulted in a further increase in the final residue. The less amount of flame retardant agent used may be the primary cause of the reduction in final mass.
Peak HRR, mean CO, TSR, and TSP values of polyester fabric samples decreased with the increasing ZnB concentration (Table 6). Zinc borate protected the substrate from the transfer of oxygen and heat by forming a vitreous char layer. Substitution of zinc borate decreased the mean CO, TSR, and TSP values of samples treated with commercial phosphorus based finishing agents. Peak HRR, THR, mean $\mathrm{CO}_{2}$ values of samples treated with PSY and PEK were also reduced. However, these values could not be further improved by the substitution of zinc borate.

The substitution of either PEK or PSY by zinc borate did not enhance the flammability properties of polyester fabrics as also shown by LOI and vertical flammability tests. Combination of zinc borate by organophosphorus based FR slightly reduced the LOI value and vertical flammability of the fabric but the mean $\mathrm{CO}$ and total smoke release values were also decreased. Therefore, PEK-ZnB combination can be preferred due to its low smoke properties and low cost. The combination of $\mathrm{ZnB}$ and PEK can be concluded to exhibit smoke suppressant properties. The addition of zinc borate, maintaining the amount of PEK or PSY, may enhance the fire performance. However, such add-on may impair the physical properties of polyester fabrics.

\section{Data Availability}

All the data used to support the findings of this study are included within the article. 


\section{Disclosure}

Some of the results included in this manuscript were presented to the COST MP1105 Final Conference, 2016.

\section{Conflicts of Interest}

The authors declare that there are no conflicts of interest regarding the publication of this paper.

\section{Acknowledgments}

This study was supported by National Boron Research Institute [grant no: 2010-Ç026] and Anadolu University Scientific Research Projects Commission [grant no: 083315].

\section{References}

[1] A. Horrocks, "Textiles," in Fire Retardant Materials, A. R. Horrocks and D. Price, Eds., Woodhead Publishing Limited, England, 2001.

[2] S. Bourbigot, "Flame retardancy of textiles: new approaches," in Advances in Fire Retardant Materials, A. R. Horrocks and D. Price, Eds., Woodhead Publishing Limited, England, 2008.

[3] A. R. Horrocks and S. C. Anand, Eds., Handbook of Technical Textiles: Technical Textile Applications, Woodhead Publishing, UK, 2000.

[4] E. D. Weil and S. V. Levchik, "Commercial flame retardancy of thermoplastic polyesters - A review," Journal of Fire Sciences, vol. 22, no. 4, pp. 339-350, 2004.

[5] J. Alongi, M. Ciobanu, J. Tata, F. Carosio, and G. Malucelli, "Thermal stability and flame retardancy of polyester, cotton, and relative blend textile fabrics subjected to sol-gel treatments," Journal of Applied Polymer Science, vol. 119, no. 4, pp. 1961-1969, 2011.

[6] J. Alongi and G. Malucelli, "State of the art and perspectives on sol-gel derived hybrid architectures for flame retardancy of textiles," Journal of Materials Chemistry, vol. 22, no. 41, pp. 21805-21809, 2012.

[7] E. Guido, J. Alongi, C. Colleoni et al., "Thermal stability and flame retardancy of polyester fabrics sol-gel treated in the presence of boehmite nanoparticles," Polymer Degradation and Stability, vol. 98, no. 9, pp. 1609-1616, 2013.

[8] A. A. Younis, K. El-Nagar, and M. A. Nour, "Part I: characterization of flammability behavior of polyester fabric modified with sol-gel," International Journal of Chemistry, vol. 5, no. 2, 2013.

[9] A. A. Younis, M. A. Nour, and K. El-Nagar, "Part II: phosphorylated sol-gel flame retardant coating for polyester fabric," in Proceedings of the 19th International Conference on Composite Materials, pp. 1-8, Canada, 2013.

[10] Z. Ömeroğulları and D. Kut, "Application of low-frequency oxygen plasma treatment to polyester fabric to reduce the amount of flame retardant agent," Textile Research Journal, vol. 82, no. 6, pp. 613-621, 2012.

[11] I. van der Veen and J. de Boer, "Phosphorus flame retardants: properties, production, environmental occurrence, toxicity and analysis," Chemosphere, vol. 88, no. 10, pp. 1119-1153, 2012.

[12] J. Alongi, J. Tata, F. Carosio, G. Rosace, A. Frache, and G. Camino, "A comparative analysis of nanoparticle adsorption as fire-protection approach for fabrics," Polymer, vol. 7, no. 1, pp. 47-68, 2015.
[13] A. R. Horrocks, "Flame retardant challenges for textiles and fibres: new chemistry versus innovatory solutions," Polymer Degradation and Stability, vol. 96, no. 3, pp. 377-392, 2011.

[14] C. Ding, J.-C. Zhang, X.-Q. Liu, X.-X. Feng, H. Zhang, and K. Lai, "Thermal performance and flammability of poly(ethylene terephthalate) fabrics grafted with different monomers followed by electron beam irradiation," Fibers and Polymers, vol. 15, no. 9, pp. 1895-1901, 2014.

[15] M. Matzen, B. Kandola, C. Huth, and B. Schartel, "Influence of flame retardants on the melt dripping behaviour of thermoplastic polymers," Materials, vol. 8, no. 9, pp. 5621-5646, 2015.

[16] B. Scharte, "Phosphorus-based flame retardancy mechanismsold hat or a starting point for future development?" Materials , vol. 3, no. 10, pp. 4710-4745, 2010.

[17] K. A. Salmeia, J. Fage, S. Liang, and S. Gaan, "An overview of mode of action and analytical methods for evaluation of gas phase activities of flame retardants," Polymer, vol. 7, no. 3, pp. 504-526, 2015.

[18] S. Bourbigot, M. Le Bras, R. Leeuwendal, K. K. Shen, and D. Schubert, "Recent advances in the use of zinc borates in flame retardancy of EVA," Polymer Degradation and Stability, vol. 64, no. 3, pp. 419-425, 1999.

[19] M. Doğan and E. Bayramli, "The flame retardant effect of aluminum phosphinate in combination with zinc borate, borophosphate, and nanoclay in polyamide-6," Fire and Materials, vol. 38, no. 1, pp. 92-99, 2014.

[20] M. Kilinc, G. O. Cakal, G. Bayram, I. Eroglu, and S. Özkar, "Flame retardancy and mechanical properties of pet-based composites containing phosphorus and boron-based additives," Journal of Applied Polymer Science, vol. 132, no. 22, 2015.

[21] Z. Wu, Y. Hu, and W. Shu, "Effect of ultrafine zinc borate on the smoke suppression and toxicity reduction of a low-density polyethylene/intumescent flame-retardant system," Journal of Applied Polymer Science, vol. 117, no. 1, pp. 443-449, 2010.

[22] J. P. Agrawal, D. C. Gupta, Y. Khare, and R. S. Satpute, "Zinc-Borate complex as flame-retardant filler," Journal of Applied Polymer Science, vol. 43, no. 2, pp. 373-377, 1991.

[23] S. Bourbigot, M. Le Bras, and S. Duquesne, "Zinc borates as synergists for flame retarded polymers," in Fire Retardancy of Polymers: New Applications of Mineral, M. Le Bras, C. A. Wilkie, and S. Bourbigot, Eds., pp. 327-335, The Royal Society of Chemistry, Cambridge, UK, 2005.

[24] K. K. Shen, S. Kochesfahani, and F. Jouffret, "Zinc borates as multifunctional polymer additives," Polymers for Advanced Technologies, vol. 19, no. 6, pp. 469-474, 2008.

[25] M. E. Üreyen, "The combined effect of organic phosphinate based flame retardant and zinc borate on the fire behaviour of poly(butylene terephthalate)," Anadolu University Journal of Science and Technology A-Applied Sciences and Engineering, vol. 17, no. 5, p. 10, 2016.

[26] T. M. Kotresh, R. Indushekar, M. S. Subbulakshmi, S. N. Vijayalakshmi, A. S. K. Prasad, and A. K. Agrawal, "Evaluation of commercial flame retardant polyester curtain fabrics in the cone calorimeter," Journal of Industrial Textiles, vol. 36, no. 1, pp. 47-58, 2006.

[27] J. Tata, J. Alongi, F. Carosio, and A. Frache, "Optimization of the procedure to burn textile fabrics by cone calorimeter: part I. Combustion behavior of polyester," Fire and Materials, vol. 35, no. 6, pp. 397-409, 2011.

[28] A. Y. Olenin, Y. A. Krutyakov, A. A. Kudrinskii, and G. V. Lisichkin, "Formation of surface layers on silver nanoparticles 
in aqueous and water-organic media," Colloid Journal, vol. 70, no. 1, pp. 71-76, 2008.

[29] T. M. Tolaymat, A. M. El Badawy, A. Genaidy, K. G. Scheckel, T. P. Luxton, and M. Suidan, "An evidence-based environmental perspective of manufactured silver nanoparticle in syntheses and applications: a systematic review and critical appraisal of peer-reviewed scientific papers," Science of the Total Environment, vol. 408, no. 5, pp. 999-1006, 2010.

[30] A. M. El Badawy, T. P. Luxton, R. G. Silva, K. G. Scheckel, M. T. Suidan, and T. M. Tolaymat, "Impact of environmental conditions ( $\mathrm{pH}$, ionic strength, and electrolyte type) on the surface charge and aggregation of silver nanoparticles suspensions," Environmental Science \& Technology, vol. 44, no. 4, pp. 12601266, 2010.

[31] A. Genovese and R. A. Shanks, "Structural and thermal interpretation of the synergy and interactions between the fire retardants magnesium hydroxide and zinc borate," Polymer Degradation and Stability, vol. 92, no. 1, pp. 2-13, 2007.

[32] Y. Yang, X. Shi, and R. Zhao, "Flame retardancy behavior of zinc borate," Journal of Fire Sciences, vol. 17, no. 5, pp. 355-361, 1999.

[33] B. Simončič, S. Hadžić, J. Vasiljević et al., "Tailoring of multifunctional cellulose fibres with "lotus effect" and flame retardant properties," Cellulose, vol. 21, no. 1, pp. 595-605, 2013.

[34] F. Laoutid, L. Bonnaud, M. Alexandre, J.-M. Lopez-Cuesta, and P. Dubois, "New prospects in flame retardant polymer materials: from fundamentals to nanocomposites," Materials Science and Engineering: R: Reports, vol. 63, no. 3, pp. 100-125, 2009. 


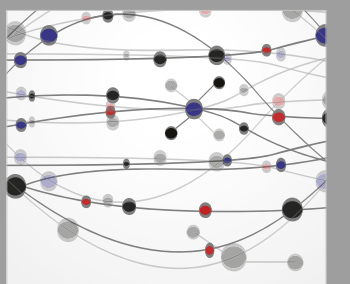

The Scientific World Journal
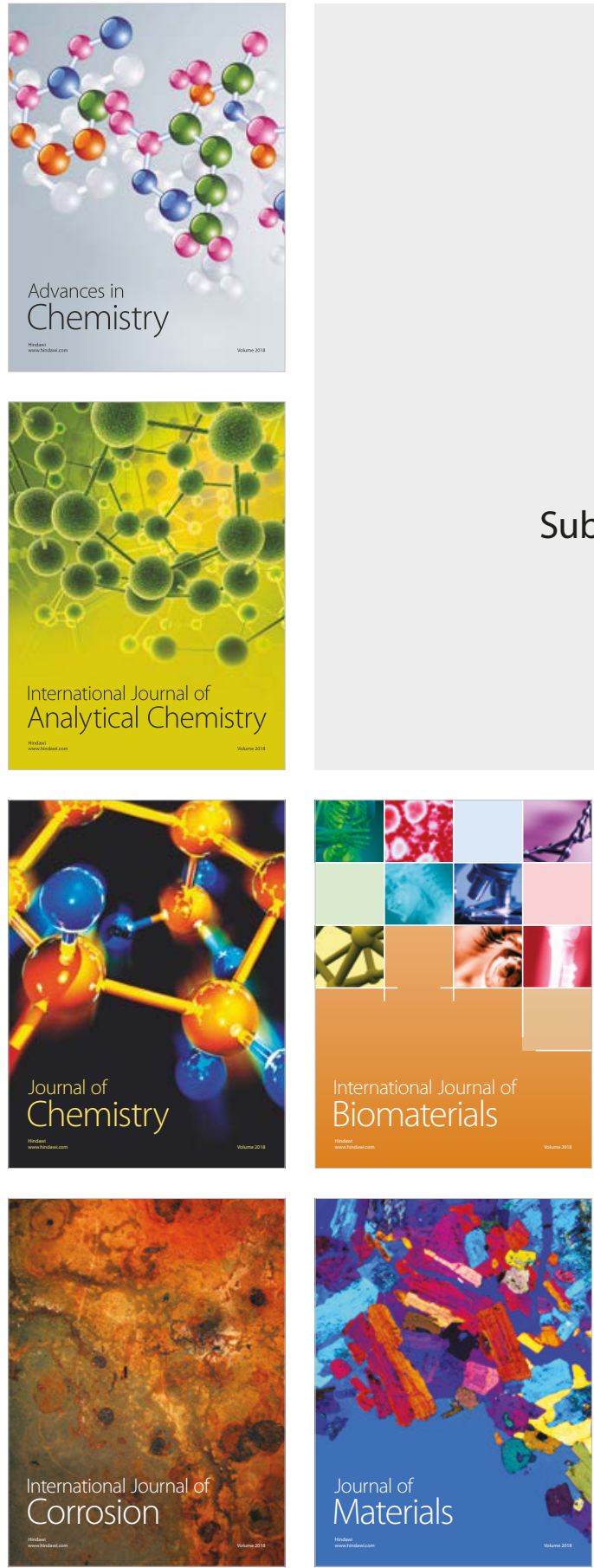

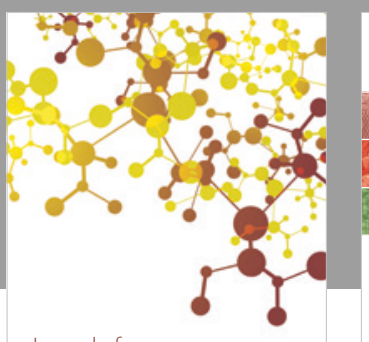

Journal of

Applied Chemistry
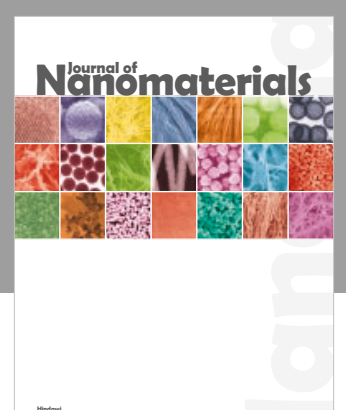

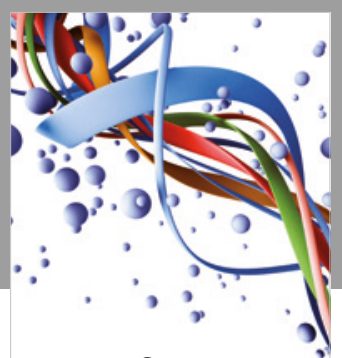

Scientifica

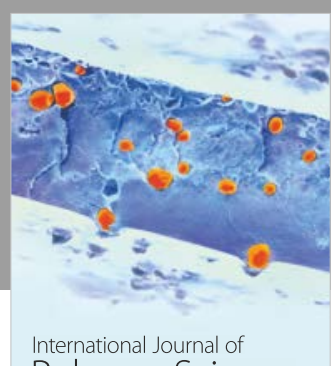

Polymer Science

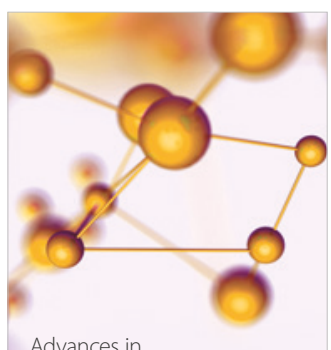

Physical Chemistry
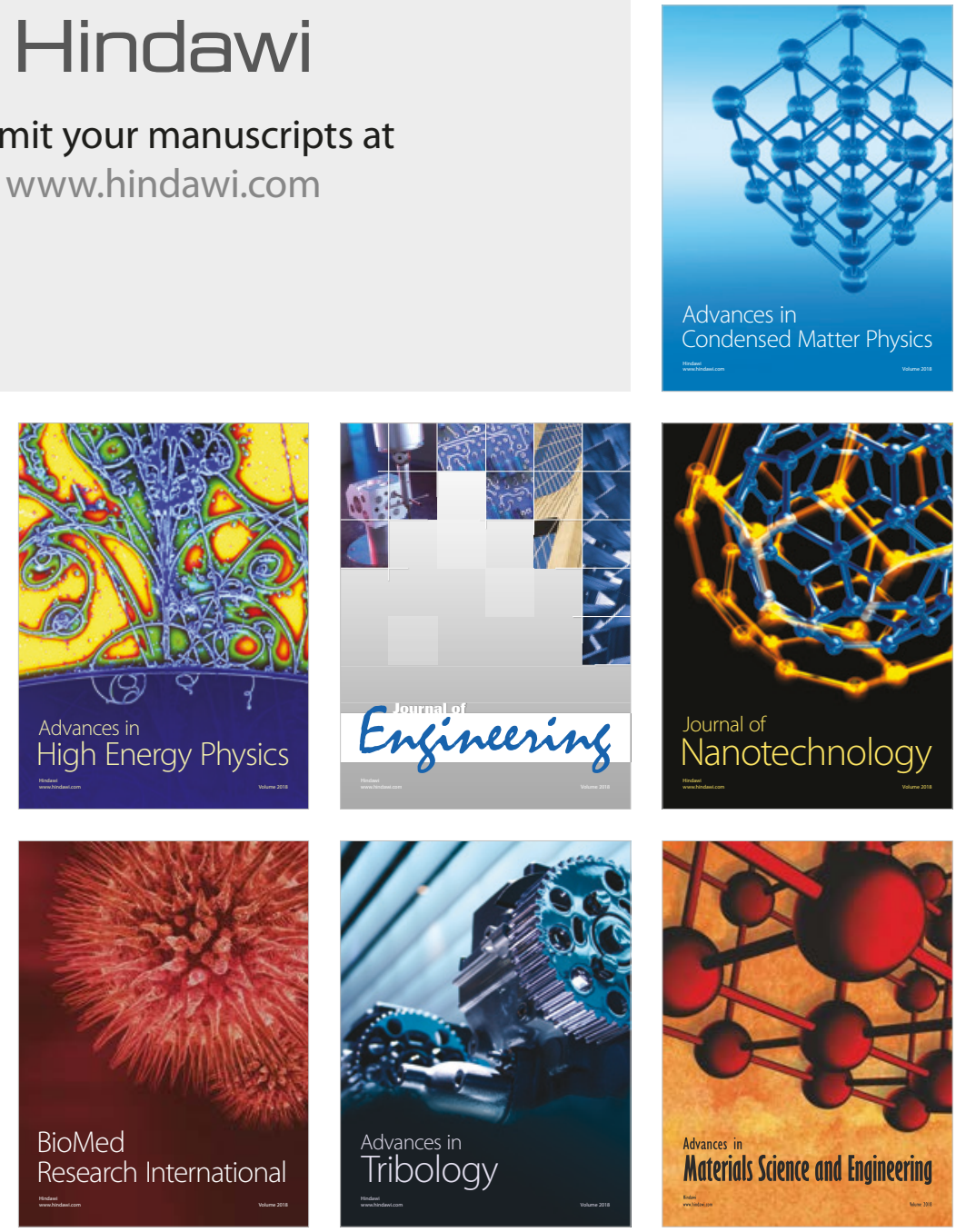